\title{
Continuous Chemistry in Microreaction Systems for Practical Use
}

\author{
Gernot Müller, Theo Gaupp, Fabian Wahl, and Gregor Wille*
}

\begin{abstract}
Handling manufacturing processes in microstructured continuous systems offers a variety of benefits to chemical as well as process performance. In this report, representative examples are given for profits in general process development, high exothermic/hazardous reactions, handling of products that are unstable under reaction conditions and product profile improvement. Specific focus was aimed at reasonable timeframes for $0.5-1 \mathrm{~kg}$ campaigns by using commercially available microreaction technology. After analyzing the individual contributions of flow technology, we assembled a competitive minimal microreaction system comprising all essential parts for running effective continuous chemistry.
\end{abstract}

Keywords: Continuous chemistry · Kilogram synthesis · Microreaction technology · Process intensification · Scale-up

\section{Introduction}

Although dating back to the late 1980s [1], the design and application of micro-structured systems for continuous liquid/liquid synthesis has made tremendous practical progress in the last decade. Along with the launch of the first commercially available systems about five years ago the general applicability of microreaction technology (MRT) to organic chemistry has been widely demonstrated [2]. Recent contributions made clear that the paradigm shift 'batch to continuous' is not carried out for the sake of itself, but gave remarkable benefits for the chemistry such as synthesis performance (Fig. 1) [3]. On lab scale, the investigation of reaction parameters out of batch-range (e.g. highly volatile solvents) even for complex biological active compounds that are only accessible in small quantities [4] becomes possible, which allows rapid access to process protocols. Enhanced process stability and improved product profiles along with opportunities for cutting energy costs [5] provoked a transition in this technology from an 'academic' lab instrument to an
${ }^{\star}$ Correspondence: Dr. G. Wille Sigma-Aldrich Production $\mathrm{GmbH}$ Industriestrasse 25

CH-9471 Buchs SG

Tel.: +418175523 33

E-Mail: gwille@europe.sial.com applicable manufacturing tool in industry [6]. Development time is shortened because continuous reactors scale output quantities as a function of operation time rather than equipment size. Such scale-independent synthesis permits direct transfer from lab protocol to manufacturing, making continuous synthesis in microreactors an ideal tool for our demands in first kilo campaigns.

\section{General System Considerations}

When we decided in winter 2003 to set up an in-house facility for regular use of a microreaction system the initial goal was to realize an output capacity of $1 \mathrm{~kg} / 8 \mathrm{~h}$ based on a (theoretical) yield of $100 \%$. Assuming a standard concentration of $1 \mathrm{M}$ and an average molecular weight of $250 \mathrm{~g} / \mathrm{mol}$,

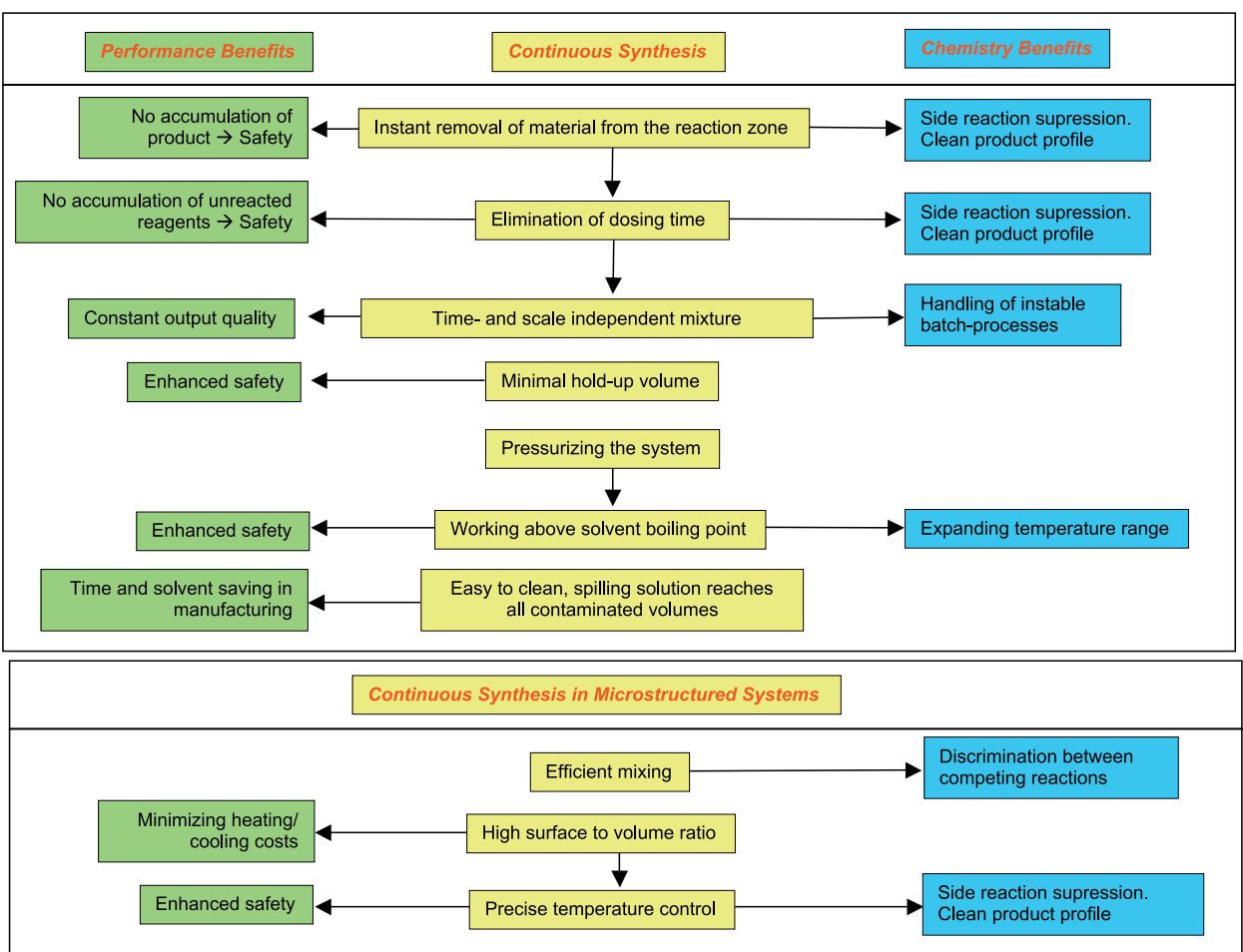

Fig. 1. Main aspects of continuous synthesis and continuous synthesis in microstructured systems (i.e. microreactors) 
a feed rate of $8.3 \mathrm{ml} / \mathrm{min} / \mathrm{channel}$ would be required to meet our initial goal. For symmetric flow rates (one line per starting material or reagent) this would result in a total flow of $16.6 \mathrm{ml} / \mathrm{min}$; a standard residence time of $10 \mathrm{~min}$ would require a residence volume of $166 \mathrm{ml}$ [7].

The set-up, as described above to reach our production goal, would consume about $30 \mathrm{~g}$ of staring material before reaching steady-state in each individual experiment of the parameter evaluation phase. Therefore the system of choice should be adaptable to diverse (smaller) reaction volumes and reduced flow rates to facilitate reaction optimization without commitment/ loss of potentially valuable starting materials. Nonetheless, residence times once identified on low flow rates should give the same results in terms of yield and product profile when reproduced on high-flow combinations (= enhanced productivity). In the case of a typical synthesis suitable for microsystems (which mainly means the absence of solids!) the direct link from parameter evaluation to manufacturing should provide scale-independent protocols within three days of labor.

On the basis of these considerations, we purchased an integrated microreaction CYTOS ${ }^{\circledR}$ Lab System (CLS) [8] in January 2004. Equipped with an external Huber Tango heater/chiller this instrument in the standard configuration (stainless steel) covers a temperature range of -20 to $+180{ }^{\circ} \mathrm{C}$, flow rates up to $20 \mathrm{ml} / \mathrm{min} /$ channel and residence volumes up to 137 $\mathrm{ml}$ (customizable into units of 2,15 and $60 \mathrm{ml})$.

\section{Applications}

The following examples have been taken from our evaluation program to show whether MRT can meet our demands in terms of productivity and/or quality gain. We present examples applicable to general process development, high exothermic/ hazardous reaction control, rapid unstable product extraction out of the reaction zone and product purity profile improvement. Key issues addressed by these examples are broad applicability of the technology, safety of operations, rapid product recovery and reduction of undesirable side products.

\section{General Process Development}

For the synthesis of mono-protected diamines, usually $\mathrm{Boc}_{2} \mathrm{O}$ is added to the diamine, resulting in a crude mixture of mono- and di-protected products accompanied by unconverted staring material. As our first experimental procedure we chose the selective Boc-protection of piperazine 1 (Scheme 1). Solvent screening indicated $\mathrm{MeOH}$ to be the solvent of choice because alternative solvents caused blockage of flow through the microreactor when the temperature fell below a certain limit. The following parameter optimization focused on the number of $\mathrm{Boc}_{2} \mathrm{O}$ equivalents and revealed that the best selectivity/conversion combination was obtained for 0.8 equiv. of acylation agent (Fig. 2, $\mathrm{MeOH}, \mathrm{T}=30{ }^{\circ} \mathrm{C}$ ). In the final experimental study, the productivity [g/h] was our optimization target. Productivity may be improved either by concentra-

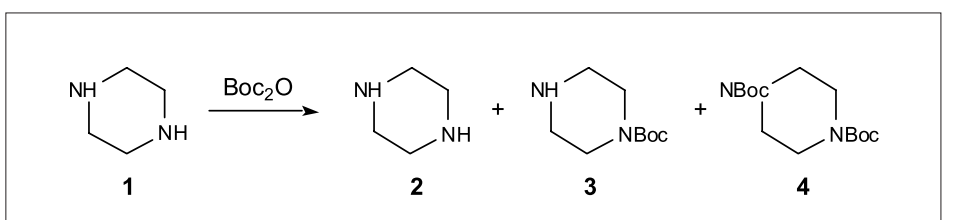

Scheme 1. Product distribution in the Boc-protection of piperazine (1)

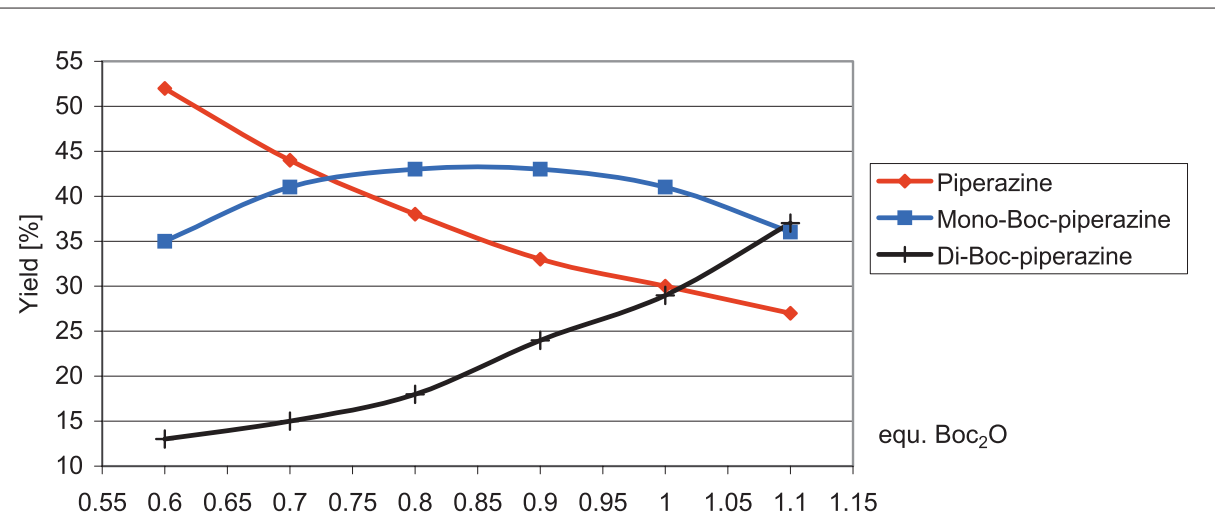

Fig. 2. Equivalent optimization of piperazine (2) mono-Boc protection. Total feed rate $4.0 \mathrm{ml} / \mathrm{min}$ (individual flow rates adapted for equivalent modification), concentration $0.2 \mathrm{M}$ in $\mathrm{MeOH}$ (each), reaction volume $76.5 \mathrm{ml}$, temperature $30^{\circ} \mathrm{C}$.

tion increase in the effluent or an enhanced flow rate through the microreactor. Prior to flow rate investigation, experiments with raised concentrations exhibited blockage at $\mathrm{c}=1.6 \mathrm{M}$ and therefore the ideal concentration of 1 was set at $\mathrm{c}=1.3 \mathrm{M}$.

In a flow system the formation of selfexpanding gas (here $\mathrm{CO}_{2}$ ) causes shortening of residence time (similar to flow rate enhancement). To explore the feeding rate limit the residence volume was kept at 76.5 $\mathrm{ml}(60+15 \mathrm{ml}$ residence time units +1.5 $\mathrm{ml}$ microreactor) and the flow rate was gradually increased. The edge was found stepping from $4 \mathrm{ml} / \mathrm{min}$ (output of 3: 597 $\mathrm{g} / \mathrm{d}$ ) to $6 \mathrm{ml} / \mathrm{min}$ when $10 \%$ of $\mathrm{Boc}_{2} \mathrm{O}$ was left unreacted (full consumption in all prior experiments).

Development of an MRT protocol for the mono-Boc protection of an arbitrary diamine in the microreaction system did not guarantee suppression of the formation of undesired side products completely. On the other hand, this exercise demonstrated that about 20 experiments (performed in two days) rapidly lead to reliable conditions for manufacturing 2 in $c a$. $600 \mathrm{~g} / \mathrm{d}$ output. The identified protocol was applicable to a series of similar diamino compounds and facilitated their manufacturing on comparable scales after only minor adaptations [9].

\section{Unstable Products under Reaction Conditions}

The cleavage of the acetate ester 5 required special care when carried out in the batch mode (Scheme 2). The product alcohol 6 is sensitive to air, light, and temperature. In order to maintain high product quality, exposure time of the material towards the optimal reaction temperature of $60{ }^{\circ} \mathrm{C}$ needed to be kept as short as possible, something hard to accomplish in batch mode. Given the variable resident time parameter of MRT protocols we saw this as a unique possible advantage upon which to capitalize, but first the transfer of technology from batch to MRT would be necessary.

To begin this study the reaction parameters from the batch mode were applied with few changes. Initial handling in the flow system provided a contact time of $39 \mathrm{~min}$ without significant loss of product quality. A key issue that arose was how to prevent the reaction from depositing solid in the flow system. A parameter scan over about 5-10 experiments arrived at the addition of $50 \% \mathrm{EtOH}$ to the aqueous $\mathrm{KOH}$ solution to assure a clear free flowing solution.

With a workable process and free flowing conditions we were able to work at optimizing productivity and purity issues. For quality maintenance in course of the work up total conversion of $\mathbf{5}$ was essential. The 


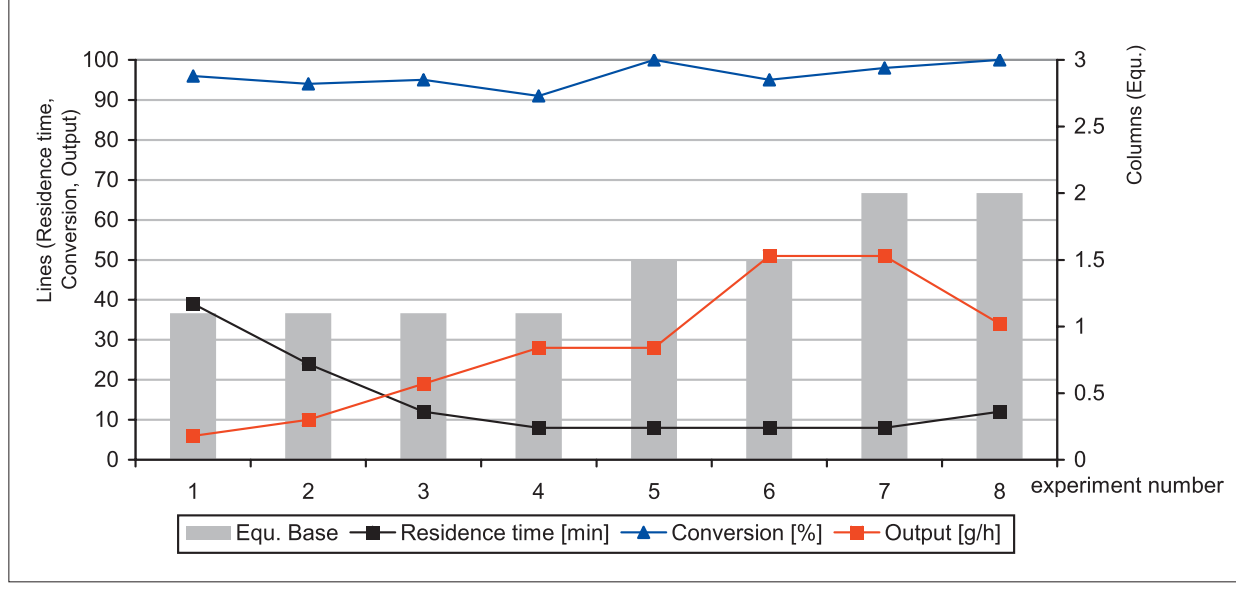

Fig. 3. Process development of the vitamin A (6) derivative synthesis

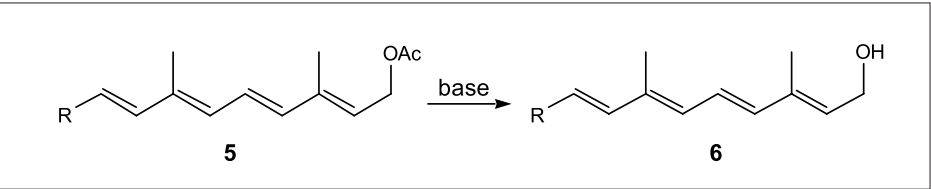

Scheme 2. Hydrolysis of vitamin A derivative 5. Conversion 100\%, yield $70 \%$. story of the further parameter optimization is summarized in Fig. 3. Experiments 1-4 show the effect of residence time reduction (realized by flow enhancement upon constant residence volume) that caused higher output but at the expense of conversion. Raising the base content by about $30 \%$ resulted in full conversion that dropped down slightly when the flow rate was doubled (doubled residence volume as well) in experiment 6. After final parameter adaptation the productivity enabled production of fully converted 6 with $270 \mathrm{~g} / 8 \mathrm{~h}$ rate (corresponding to $700 \mathrm{~g} /$ day when running the machine overnight).

\section{Highly Exothermic and/or Hazardous Reactions}

Certainly the most popular advantage of MRT is its excellent temperature control due to the large surface to volume ratio when compared to batch reactors [10]. This permits reliable handling of aggressive reagents [11] with minimal prior safety investigation (e.g. DSC). In our particular example, diketene provides a potential explosive hazard, whereas carbon tetrachloride use is potentially limited by its exposure restrictions.

Synthesis of $\mathbf{8}$ in a microstructured system enabled the safe implementation of explosive diketene (7) along with the use of highly toxic and carcinogenic carbon tetrachloride (Scheme 3) [12]. Potential risk was minimized by keeping the holdup volume in the reaction chamber below $50 \mathrm{ml}$ expanded by a downstream stirring cascade any appreciable accumulation of the reagents. Conducting the reaction in continuous manner opened the opportunity for subsequent submission of unstable intermediate $\mathbf{8}$ directly to the amine-addition step, in order to prevent $\mathbf{8}$ from potential degradation [13]. In total $10 \mathrm{~kg}$ of product $\mathbf{1 0}$ were synthesized in ten days of operation time (output rate of $8>1 \cdot 1 \mathrm{~kg} / 24 \mathrm{~h}$ ).

\section{Product Profile Improvement}

Similar to the synthesis of $\mathbf{6}$ the internal cyclization of 1,5-hexadiene (11) profited from quick extraction of the reaction mixture out of the reaction zone (Scheme 4). Moreover this far from robust synthe- sis required precise control of the reaction parameters, as suggested by preliminary experimental results: minimum temperature of $55-58{ }^{\circ} \mathrm{C}$ for reasonable conversion rates;

ii) The reaction was found to generate remarkable amounts of heat;

iii) The obtained material $\mathbf{1 2}$ underwent isomerization to $\mathbf{1 3}$ in the presence of to very similar boiling points the content of isomer $\mathbf{1 3}$ had to be kept strictly below $0.7 \%$ in the raw mixture to match product 12 specification of $+99 \%$ purity [14].

The combination of reactivity issues created a special set of process problems. The exothermic character of the cyclization required moderate dosing rates that, however, resulted in extended contact times. Extended contact time implied a higher degree of isomerization of $\mathbf{1 2}$ to $\mathbf{1 3}$. This complex interdependency of parameters excluded the synthesis from production in batch mode.

Technically, the temperature limit for the reactivity of the catalyst, in combination with the boiling point $\left(59-60{ }^{\circ} \mathrm{C}\right)$ of reagent $\mathbf{1 1}$, required sealing of the systems outlet with a pressure release valve. Finally, working at 1.0-2.0 bar inner pressure and reaction temperatures significantly above the reagents' boiling points provided a protocol for the production of 500-700 $\mathrm{g}(6-8.5 \mathrm{~mol})$ amounts of $\mathbf{1 2}$ in the above fixed $8 \mathrm{~h}$ timeframe. The content of isomer 13 was clearly connected with the conversion rate but found to be tunable by inner pressure adjustment and was kept within specifications. i) The transition metal catalyst required a catalyst even at room temperature. Due

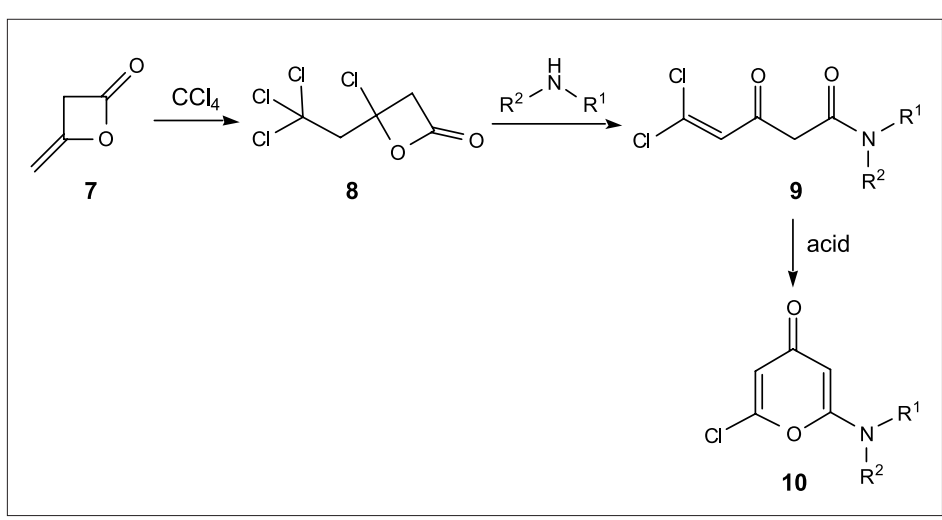

Scheme 3. Addition of carbontetrachloride (initiated by radical starter) to diketene and cyclisation provided pyrone 10

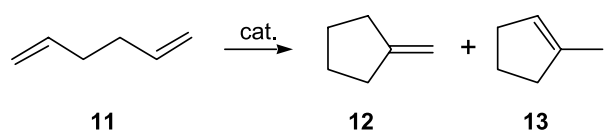

Scheme 4. Transition metal catalysed cyclisation of 1,5-hexadiene (11) 


\section{Analysis}

For a global survey, the major benefits of continuous synthesis (in microstructured systems) are correlated with the four example reactions in the Table. Although these examples definitely do not represent the entire range of organic chemistry they give an indication of the main characteristics of handling synthesis in continuous systems. The frequently quoted advantages arising from the high surface-to-volume-ratio in microstructured systems significantly applies in one case. Considerably more often simply running the conversion in a continuous manner contributed to process safety and improved product profile due to short contact times. The ratio of 9/4 confirms the impression that organic synthesis mainly benefits from continuous conduct and sophisticated microdimension design may have less important impact [15] unless specifically demanded by sensitive reactions [16].

Acceleration of chemical development processes requires fast lab scale to manufacturing transfer. In these presented examples protocol transfer from low-flow screening experiments (low material consumption) to manufacturing output rates worked reliably. In all cases an acceptable manufacturing output rate of $0.5-1.0 \mathrm{~kg} / 8 \mathrm{~h}$ was realized or the system was adjusted to a mode that would allow running overnight to fulfill the gap to the required product amount.

In the standard version the installed CYTOS $^{\circledR}$ Lab System is equipped with pressure and temperature sensors attached to supervising software. This includes an automatic shut-down function if the pressure limit is exceeded (caused by inner blockage) such as upon pump malfunction and enabled personal-independent overnight operation.

In terms of yield MRT gave similar or slightly improved results but the impact to selectivity enhancement was more significant. However, constant and scale-independent product quality was verified by in-process-control (IPC) taken at regular intervals. This fulfilled our expectations in performance improvement.

\section{Conclusion / Perspective}

The chemical development department in our company clearly profits from contin-

Table. Correlation of the reactions described in the text with the main aspects of continuous synthesis and continuous synthesis in microstructured systems. The cleaning aspect from Fig. 1 applies to all reactions and was skipped for clarity reasons.

\begin{tabular}{|c|c|c|c|c|c|c|}
\hline Process & $\begin{array}{l}\text { Continuous } \\
\text { Synthesis } \\
\text { Benefits }\end{array}$ & $\begin{array}{l}\text { Performance } \\
\text { Benefits }\end{array}$ & $\begin{array}{l}\text { Chemistry } \\
\text { Benefits }\end{array}$ & $\begin{array}{l}\text { Continuous } \\
\text { Synthesis } \\
\text { in Micro- } \\
\text { structured } \\
\text { Systems }\end{array}$ & $\begin{array}{l}\text { Performance } \\
\text { Benefits }\end{array}$ & $\begin{array}{l}\text { Chemistry } \\
\text { Benefits }\end{array}$ \\
\hline $\begin{array}{l}\text { 1. Selective } \\
\text { Mono-Boc- } \\
\text { Protection }\end{array}$ & $\begin{array}{l}\text { Time- and } \\
\text { scale } \\
\text { independent } \\
\text { mixture } \\
\text { composition }\end{array}$ & $\begin{array}{l}\text { Constant } \\
\text { output quality }\end{array}$ & & $\begin{array}{l}\text { Efficient } \\
\text { mixing }\end{array}$ & & $\begin{array}{l}\text { Discrimin- } \\
\text { ation between } \\
\text { competing } \\
\text { reactions }\end{array}$ \\
\hline \multirow{2}{*}{$\begin{array}{l}\text { 2. Hydrolysis } \\
\text { of vitamine A } \\
\text { derivative }\end{array}$} & $\begin{array}{l}\text { Instant } \\
\text { removal of } \\
\text { material from } \\
\text { the reaction } \\
\text { zone }\end{array}$ & $\begin{array}{l}\text { Side reaction } \\
\text { supression. } \\
\text { Clean product } \\
\text { profile }\end{array}$ & & & & \\
\hline & $\begin{array}{l}\text { Instant } \\
\text { removal of } \\
\text { material from } \\
\text { the reaction } \\
\text { zone }\end{array}$ & & $\begin{array}{l}\text { Constant } \\
\text { output quality }\end{array}$ & & & \\
\hline \multirow{2}{*}{$\begin{array}{l}\text { 3. Addition } \\
\text { of carbonte- } \\
\text { trachloride } \\
\text { towards } \\
\text { diktene }\end{array}$} & $\begin{array}{l}\text { Instant } \\
\text { removal of } \\
\text { material from } \\
\text { the reaction } \\
\text { zone }\end{array}$ & $\begin{array}{l}\text { No } \\
\text { accumulation } \\
\text { of unreacted } \\
\text { reagents } \rightarrow \\
\text { Safety }\end{array}$ & $\begin{array}{l}\text { Side reaction } \\
\text { supression. } \\
\text { Clean product } \\
\text { profile }\end{array}$ & $\begin{array}{l}\text { High surface } \\
\text { to volume } \\
\text { ratio }\end{array}$ & $\begin{array}{l}\text { Minimising } \\
\text { heating/ } \\
\text { cooling costs }\end{array}$ & \\
\hline & $\begin{array}{l}\text { Minimal hold- } \\
\text { up volume }\end{array}$ & $\begin{array}{l}\text { Enhanced } \\
\text { safety }\end{array}$ & & $\begin{array}{l}\text { Precise } \\
\text { temperature } \\
\text { control }\end{array}$ & $\begin{array}{l}\text { Enhanced } \\
\text { safety }\end{array}$ & \\
\hline \multirow{2}{*}{$\begin{array}{l}\text { 4. Catalysed } \\
\text { cyclisation } \\
\text { of } 1,5 \text {-hexa- } \\
\text { diene }\end{array}$} & $\begin{array}{l}\text { Instant } \\
\text { removal of } \\
\text { material from } \\
\text { the reaction } \\
\text { zone }\end{array}$ & $\begin{array}{l}\text { No } \\
\text { accumulation } \\
\text { of unreacted } \\
\text { reagents } \rightarrow \\
\text { Safety }\end{array}$ & $\begin{array}{l}\text { Side reaction } \\
\text { supression. } \\
\text { Clean product } \\
\text { profile }\end{array}$ & $\begin{array}{l}\text { Precise } \\
\text { temperature } \\
\text { control }\end{array}$ & & $\begin{array}{l}\text { Side reaction } \\
\text { supression. } \\
\text { Clean product } \\
\text { profile }\end{array}$ \\
\hline & $\begin{array}{l}\text { Working } \\
\text { above solvent } \\
\text { boiling point }\end{array}$ & & $\begin{array}{l}\text { Expanding } \\
\text { the } \\
\text { temperature } \\
\text { range }\end{array}$ & & & \\
\hline Sum & & 5 & 4 & & 2 & 2 \\
\hline
\end{tabular}

uous chemistry application. Unfortunately, its widespread distribution was restricted by the high price of integrated systems that fulfill manufacturing requirements. Recently the scope of individual commercially available microreactors (namely made from glass) was significantly expanded compared to the situation when we initiated the first MRT projects. This situation and the above learned lessons led us to the design and assembly of a minimal system for laboratory use with output capacity up to some $100 \mathrm{~g}$ amounts per day [17].

Proper and reliable control of temperature, flow rate and resident time/volume are important features that needed attention in the minimal system. Accepting that the temperature control does not necessarily need to match the end-of-the-line standards, the microreactor (mixer) was positioned in a regular heating bath along with the residence time unit. Flexible residence times were realized by attaching PTFE tubes in individual lengths to the microreactors outlet. Although syringe pumps work free of pulsation, their practicability for large-scale synthesis is limited because of interrupted work mode that requires valve-operated refilling. Installation of the stand-alone rotation pistons pumps allowed benchmark reproduction of the synthesis results for the vitamin A derivative 6 (700 g scale).

Essential elements for safe synthesis handling in continuous manner are permanent temperature and pressure monitoring. Therefore the minimal system is equipped with pressure and temperature sensors (pressure sensors death volume $<0.1 \mathrm{ml}$ ). In order to realize personal-independent operation (e.g. overnight) an electronic control unit is attached to the minimal system, including automatic shutdown function if the limit is exceeded [17]. Constructing the microreactor from glass facilitated its design adaptation according to specific requirements of the individual process (if needed), lowered costs and expanded its scope (acids, acid chlorides, nitrations etc.).

Speaking technically, we believe this minimal system will serve as a catalyst to minimize the (mainly financially raised) activation energy on the approach to the benefits of MRT to a low level which is easily conquerable by a small investment in equipment and training. As an equivalent to exergonic enthalphy (i.e. driving force) at the end of a chemical reaction, the switch to MRT manufacturing protocols will simply generate process efficiency.

Received: July 4, 2006

[1] a) W. Loehder, L. Bergann (Akademie der Wissenschaften der DDR), DD 246257, 1986; b) K. Schubert, W. Bier, G. Linder, D. Seidel, Chem. Ing. Tech. 1989, 61, 172. 
[2] a) H. Pennemann, P. Watts, S.J. Haswell, V. Hessel, H. Loewe, Org. Process Res. Dev. 2004, 8, 422; b) T. Schwalbe, V. Autze, G. Wille, Chimia 2002, 56, 636; c) K. Jaehnisch, V. Hessel, H. Loewe, M. Baerns, Angew. Chem. Int. Ed. 2004, 43, 406 and literature quoted therein; d) P.D.I. Fletcher, S.J. Haswell, E. PomboVillar, B.H. Warrington, P. Watts, S.Y.F. Wong, X. Zhang, Tetrahedron 2002, 58, 4735.

[3] a) X. Zhang, S. Stefanick, F.J. Villani, Org. Process Res. Dev. 2004, 8, 455; b) N. Schwesinger, O. Marufke, F. Qiao, R. Devant, H. Wurziger, Process Miniaturization - IMRET 2: 2nd International Conference on Microreaction Technology, New Orleans, USA, 1998: Topical Conference Preprints, (Ed. W. Ehrfeld, I.H. Rinard R.S. Wegang, American Institute of Chemical Engineers, p. 124; c) C. Wiles, P. Watts, S.J. Haswell, E. Pombo-Villar, Lab Chip 2001, 1, 100; d) P. Watts, C. Wiles, S.J. Haswell, E. Pombo-Villar, Tetrahedron 2002, 58, 5427.

[4] D.M. Ratner, E.R. Murphy, M. Jhunjhunwala, D.A. Snyder, K.F. Jensen, P.H. Seeberger, Chem. Commun. 2005, 5, 578.

[5] a) D. Kralisch, G. Kreisel, A. Stark, 'Assessment of the Ecological Potential of Microreaction Technology' Spring 2005 AIChE National Meeting, New York, USA, 2005; b) D. Kralisch, G. Kreisel, Chem. Ing. Tech. 2005, 77, 784.
[6] DECHEMA Trendreport Nr. 17, 2006: Microtechnology, www.achema.de; b) A.M Thayer, Chem. Eng. News 2005, 83, 43; c) D.M. Roberge, L. Ducry, N. Bieler, P. Cretton, B. Zimmermann, Chem. Eng. Tech. 2005, 28, 318. The latest highlight of microstructured applications in industry represents the nitroglycerin production unit operating under cGMP-standards (!) that was launched by Institut fuer Mikrotechnik Mainz $\mathrm{GmbH}$ (D) and Xi'an Chemical Group (PRC), see: IMM press release November 9, 2005, www.immmainz.de.

[7] Residence time $=$ residence volume/flow rate.

[8] CPC-Systems GmbH, Heiligkreuzweg 90, D-55130 Mainz, www.cpc-net.com Upgrades of the CYTOS ${ }^{\circledR}$ Lab System to working temperatures of $-40{ }^{\circ} \mathrm{C}$ and constructions from Hastelloy are available. As part of a closed product family, production parameters identified with the CYTOS ${ }^{\circledR}$ Lab System are applicable to the 10-fold numbered up CYTOS ${ }^{\circledR}$ Pilot System for output multiplication, T. Schwalbe, A Kursawe, J. Sommer, Chem. Eng. Tech. 2005, 28, 408.

[9] N-Boc-2,2-(ethylendioxy)-diethylamine (Fluka product number 89761), N-Boc4,7,10-trioxa-1,13-tridecantriamine (Fluka product number 93113), N-Bochomopiperazine (Fluka product number 17759).
[10] Exemplary surface-to-volume ratios: Flatchannel microsystem, $c a$. 100-200; round bottom flask (volume $100 \mathrm{ml}$ ), 1.0; industrial reactor (volume $1 \mathrm{~m}^{3}$ ) $<0.1$.

[11] a) R.D. Chambers, D. Holling, R.C.H. Spink, G. Sandford, Lab Chip 2001, 1, 132; b) G. Panke, T. Schwalbe, W. Stirner, S. Taghavi-Moghadam, G. Wille, Synthesis 2003, 2827.

[12] $\mathrm{CCl}_{4}$ : Maximum exposure concentration $10 \mathrm{ppm}$, carcinogen category IIIB (German MAK value); diketene: $\mathrm{E}=1500 \mathrm{~J} / \mathrm{g}$. Because of confidential reasons the full structure of $\mathbf{1 0}$ cannot be disclosed.

[13] For handling instable intermediates in two-stage microreactor assemblies see: T. Schwalbe, V. Autze, M. Hohmann, W. Stirner, Org. Process Res. Dev. 2004, 8, 440.

[14] Fluka product number 66763.

[15] a) V. Hessel, H. Loewe, P. Loeb, Chem. Tech. 2006, 5, 24; b) S. Hikage, J. Yoshida, 'Highly Selective Halogen-Li Exchange Reaction Using Microreactors' 2nd International Workshop on Microchemical Plant, Kyoto, Japan, 2004.

[16] S. Suga, A. Nagaki, J. Yoshida, Chem. Commun. 2003, 354.

[17] Evaluation of the minimal system and inhouse distribution to small-scale production labs is currently finished. The system will be available on the market from September 2006 as 'Microreaction Explorer Kit', Fluka product number 19979. 